\title{
"THY GLASS WILL SHOW THEE" RE-LOCATING VOICE IN SHAKESPEARE'S SONNETS bY PERFORMATIVE SPECULATION
}

\author{
ALFREDO MICHEL MODENESSI \\ Universidad Nacional Autónoma de México \\ Pareciame en todas las partes de mi alma le veía \\ claro como en un espejo, y también este espejo, yo \\ no sé decir cómo, se esculpía todo en el mismo \\ Señor por una comunicación que yo no sabré decir, \\ muy amorosa.
}

Teresa de Ávila, Libro de la vida, 40:5

Late in her career, Sor Juana Inés de la Cruz seemed surprised to learn that her poetry had been highly praised by some of her Spanish contemporaries. She responded with a poem where pride and modesty playfully combine into a riddling ending:

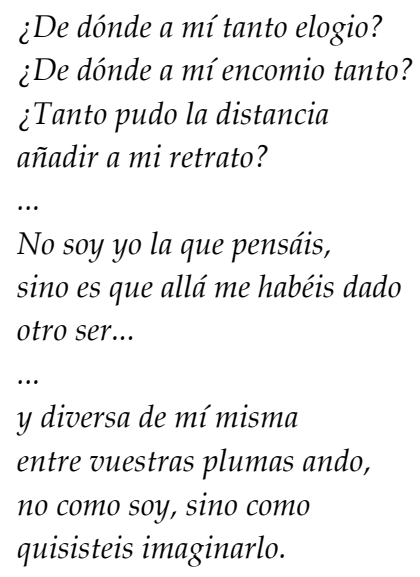


At first glance, Sor Juana's response seems modestly, though also amusedly, intended to dismiss "praise" as the unmerited result of a "distance" (lack of real acquaintance with her work) that added "too much" to what she terms "my portrait". But let us remember that, for her, "retrato" (portrait) was synonymous with "engaño colorido" - "a colorful deceit", a fiction of poetic self rather than a poetic self-portrait, itself a fiction. In the end, she sees herself "different from myself", transformed by the perception of those who praised her, reflected in their "willing imagination". This distinction suggests that the "self" that her Spanish contemporaries "gave her" was alien to what was already alien to herself: a self constructed by imaginative readers turned writers of a fiction on a fiction.

Should we consider ourselves lucky that Sor Juana had first-hand knowledge of the first among the manifold constructions made of her work - and of her "self" - while she was still alive? That she could at once gracefully enjoy such constructions and dismiss them? Should we think her response personal, straightforward and transparent and hence representative of "authorial intention"? In other words, given that her response to her colleagues' praise is such a superb instance of ironic "self[un]fashioning", should we consider it self-expressive or, in a modern sense, lyrical? It isn't hard to say: no we shouldn't. Her disclaimer characterizes her work as the outcome of an outstanding intellect capable of producing numerous "portraits" avowedly not in her likeness. Sor Juana's "true self" remains elusive, the happy center of much debate and speculation. The artistic awareness, sharp sense of humor, and verbal playfulness that pervades her poetry - and the poetry of many others in the $17^{\text {th }}$ century are much to blame for this unceasing interpretive tension. Since she frequently directs her reader after this fashion: "Óyeme con los ojos, / ya que están tan distantes los oídos", 1 depending on the beholder's "eye[I]", the voice that readers "hear" from her poems rings indifferently near or far. Better yet, near and far.

This tension between "dramatic" and "lyrical" readings of Sor Juana's poetry resembles the one that sometimes emerges when the issue of voice in Shakespeare's sonnets is engaged, whether overtly or implicitly. The combination of an early modern indeterminacy of literary genre with the 
enormous range of their voice makes the strict application of either label to Shakespeare's sonnets at worst pointless, and at best indicative of how strongly they demand, and more often than not elicit - in contrast with precedents that employ more sequential or consequential approaches to poetic composition - a performative commitment from their interpreters prior to critical elucidation; i.e. they provoke the implicit (re)creation of a fiction, say a soliloquy or mental dialogue, heavily charged with the reader's frame of reference as the inevitable source of the ensuing evaluation - like the one Sor Juana claims her Spanish counterparts employed in her case.

The persuasiveness of a particular interpretation of a Shakespeare sonnet may depend on performative premises and effects, indeed. For instance, despite evident affinities between Helen Vendler's and Michael C. Schoenfeldt's accounts of sonnet 129, their interpretations ultimately and tellingly differ much due to the particular ways in which they perceive the sonnet to unfold as its words turn into action - as they constitute a series of acts of speech; that is, Schoenfeldt and Vendler differ regarding the performative premises each applies although they both implicitly recognize a dramatic quality to the sonnet.

Th'expense of spirit in a waste of shame

Is lust in action; and till action, lust

Is perjured, murd'rous, bloody, full of blame,

Savage, extreme, rude, cruel, not to trust;

Enjoyed no sooner, but despiséd straight;

Past reason hunted, and no sooner had,

Past reason hated as a swallowed bait,

On purpose laid to make the taker mad;

Mad in pursuit, and in possession so;

Had, having, and in quest to have, extreme;

A bliss in proof, and proved, a very woe;

Before, a joy proposed, behind, a dream.

All this the world well knows, yet none knows well

To shun the heaven that leads men to this hell. ${ }^{2}$ 
Schoenfeldt inflexibly reads the sonnet as Shakespeare's "demonstrat[ion] that [sex] is not a consummation devoutly to be wished, but rather a nightmare that cannot be avoided" where "the imagined physiology of sexual intercourse underpins a visceral disgust with the entire enterprise of corporeal hunger and physical satiation" (Schoenfeldt 82). Vendler, instead, sees it as "a text [that] encourages us to invent ... a sensibility and its ... changing responses to lust" leading to a "third layer of ironic knowledge" where "we see still the two underpaintings ... the first of a post-erotic hell, the second of a brief erotic heaven" (Vendler 550, 553). The differences are all too clear. Schoenfeldt sees the sonnet as a "demostration", a set of images that together constitute a fixed or static statement of fact, or a closed and homogenous definition merely illustrated several ways. Vendler perceives a process ("changing responses") in interaction with the reader ("encourages us to invent") which is more in keeping with the dynamism that characterizes Shakespeare's work; one that, it must be remembered even if it seems too patent - consists mostly of fictional voices other than the writer's, dramatic voices. This is among the strongest features of Shakespeare's emerging modernity: the openness of his art, its capacity to engage the mind in inquisitive interlocution.

While Schoenfeldt's erudition makes his account intellectually very stimulating, his assumption of a closed, declarative and authoritative "lyrical" voice in the sonnet seems to prevent him from stepping one inch off the path of monotone (re)delivery of well-known, and probably forcibly learned maxims. The voice he hears and replicates is as personal and rigid as it is irrevocably at odds with "the ephemeral nature of ... pleasures" (Schoenfeldt 83), and makes no room for irony or for any other complex variation of tone, let alone a sense of humor. Vendler's approach imports the existence of an artistic challenge at the core of the sonnet and allows for her description of dynamic composition to operate with a much wider spectrum of tonality over her exegesis of its content, which, in her view, is possibly but not necessarily self-expressive. The sense of complex drama that runs through her account, and her grasp of time as an active factor - best displayed in her characterization of the poem as a feat of truthful duplicity at crucial times demanding the use of an impersonal voice - make reading 
Vendler pleasurably close to listening to a live and enlivening delivery. The contrasting dialogue between these two critical performances evinces the breadth of voice in the sonnets. It also suggests that such an ample range can easily accomodate other, less authorized, interpretations - better still, speculations - involving performance.

For instance, reading 129 along a combination of the inflexible voice that Schoenfeldt hears as Shakespeare's and Vendler considers initially impersonal and then, in the third quatrain, mere "pretense" (her "homiletic" voice: Vendler 550), may prompt a lighter but valid alternative reading in the form of a performative scenario for one player within a very simple frame of dramatic delivery. To this purpose, it would help to consider that what Schoenfeldt identifies as a series of categorizations made with "clinical precision" (Schoenfeldt 82), and Vendler terms "a retrospective vision" (Vendler 550), can likewise be described as their respective responses to a dramatic variation - a variation operating as progessive action in fictional present time - on a poetic configuration by no means unusual: that of a sonnet containing an ennumeration, or a variant of an ennumeration, apparently aiming at a definition of an abstract object, traditionally love, whereby the poet seeks to convey the conflicts such object conventionally provokes, perhaps with an aim to contribute a reflection on the matter. ${ }^{3}$ With Shakespeare, however, the object of definition and the definition of the object differ significantly from the conventional understanding of both object and method of definition - as Schoenfeldt notes: "Erotic attraction here is not an avenue to the divine" (Schoenfeldt 83) - and the supposedly closing reflection (the couplet) is characteristically ambiguous.

In the aforementioned hypothetical scenario a player would deliver the first eight lines of 129 impersonally because all of them constitute an account of received notions of lust: notions not originating from his own consciousness or convictions, and thereby not spoken in his voice but only through his voice as the vehicle to convey his memory of those notions by ennumerating them. The player would not necessarily "remember" these lines from a single source but as if they had pooled together in the present single source, the speaker himself, and were now re-emerging in the 
singleness of his voice. This, however, does not imply that they should be delivered in a single tone. Some lines are bookish; others, perhaps a majority, came to him from a pulpit at a younger age. The lines have been in his mind for some time, and now, for whatever reason, seem relevant to his situation. He personates their original sources partly, and partly comments on them as he does so, perhaps bitterly, perhaps ironically; maybe he overstresses, maybe downplays, some. What remains certain is that he is ennumerating things he has heard or read and internalized, now worth recalling, not so as to re-state them as indisputable truths, but because they constitute the fundamental text of a present "acting of a dreadful[ly confusing] thing" that can also, without further contradiction, be amusing. Throughout, there may be a sense of growing discomfort, even displeasure, though always controlled by a degree of skepticism regarding what is being delivered - which, again, is not the speaker's mind but his memory of others' minds and words spoken therefrom.

Our player now reaches quatrain three, which Vendler finds impossible to treat as pronounced by "a cleric" (Vendler 550). But its first line famously picks up the "mad" that closes line eight. Does the term not establish a continuum between the three quatrains which, nonetheless, as usual with Shakespeare, can as well be described as operating independently or even at odds with each other? In other words, is there really an octave/ sestet division in this sonnet? And the "extreme" of line ten - which Vendler places at the core of her reading and treats in near-isolation from its immediate context - is it only "neutral" (Vendler 552)? Lines eleven and twelve could make it specific if read as providing examples of extremity: i.e., as enlisting further terms synonimous with lust ("a bliss", "a very woe", "a joy", "a dream") that are all consistent with her explication of "extreme": "going past the mean of reason in all directions" (Vendler 552). The same lines eleven and twelve might hence be read as a cleric's choice illustrations of how lust darkens all sense of reality. In the present scenario, quatrain three, like the rest, would of course not be pronounced by a cleric but by our player. Still, our player would pronounce most of it as if he remembered hearing a stern preacher deal with lust in "exemplary" manner. ${ }^{4}$ The player's 
displeasure or discomfort may now be toned down in preparation for the couplet.

"All this" our player knows well, and knows the world to know as well, because it is "knowledge" in the simplest, the most common sense of the word. And what it "demonstrates" in this scenario is nothing. Nothing, that is, but what the audience may obtain, if at all, as "demonstration" from the player's delivery of the couplet as an act of skepticism with respect to the topical opinions on sex ennumerated through the sonnet. Read thus, 129 becomes a dramatic, open, text involving the performance of a recollection of external input (three quatrains of unpersuasive topical information) for the player to develop a personally defined output (a couplet delivered in prehaps half-cynical, certainly humorous fashion) in connection to his character's present, dramatically "personal", circumstances. Such circumstances, of course, need not be defined rigidly but remain open to choice either by the player alone or by any combination of participants in the scenic process. The range of options is as "extreme" as "the world". In sum, 129 , would play out as a simple process where someone recalls other people's reasons why sex should be avoided but reacts to that recollection with a humorous half-agreement that agrees to nothing, where heaven and hell become interchangeable as very relative terms with regard to the nuances of sex, which, in turn and more importantly, remains irreducible.

With the inveterate meddlesomeness of dramaturgs, I would also suggest that because of the saturation of the poem with mutually exclusive options, "heaven" and "hell" should be treated indistinctly; and also that the pun on the writer's name (well = Will[iam]) enables an ambiguous take on the couplet anywhere between playful self-reference and desperate axiom, or viceversa: playful axiom and desperate self-reference - that is, a vast, horizontal, set of performative options. I would actually favor playful selfreference and axiom at once - a horizontal/vertical collusion of the options. Still, our player would be left alone to either: A) drown in a sea of disgust, self-reproach, and guilt, in apparent agreement with the "troubling" input on lust (not my option); or B) deliver the couplet in punch-line fashion, ironically questioning the validity of the presumably troubling input (closer 
to the reading above). There is, of course, option C) do something in between.

I do not mean to propose that anything goes, however. A case in favor of a "troubled" reading of this sonnet, like Schoenfeldt's, may indeed be made from comparison with others where sex is negatively problematized. ${ }^{5}$ On the other hand, I have never found an exclusively "troubled" reading of sonnet 129 pesuasive, because it depends on altogether neglecting the sense of humour that informs much of it (and many of the other 153), for example, by disallowing ironic exaggeration in the ennumeration in favor of a plain "grieving" delivery of its richly nuanced lines. In other words, should 129 be exclusively considered the very emblem of disgust with sex and sexuality, something would happen with it similar to what happens with sonnet 116, that has been eternized as a commonplace of Shakespeare's ultimate statement of love steadfast and true. When we read 116 in complete isolation, overlooking the existence of the much forgotten 117, its egregious mirror-image (converse image), we miss the sense of irony, the richness involved in the fact that Shakespeare's "meaning", being dramatic, more often than not takes place in the spaces, and even in the interstices, between words, lines, characters and situations; in the case of the sonnets that do operate consecutively, it also occurs in the space between them.

But my scenario is exactly that, a scenario - a dramaturgical project that seeks to provide a performative frame for performative purposes. In this context, however, it also serves the specific goal of illustrating an actualization of the dramatic potential that underlies this and other sonnets by Shakespeare in keeping with an artistic principle: that the dramatic mind does not seek to find out what a text is as a single or exclusive statement of fact, but aims to find in the source text legitimate but not exclusive materials so as to actualize them in the form of a derivative text (a scenario), which then becomes a particular performance. In other words, the dramatic artist seeks to bring the text to action, which is something of a platitude but also too often disregarded. In this sense it must be added, I daresay not against the enormous variety of readings that 129 has provoked but in keeping with the resilience such variety entails, that a scenario for this sonnet will ultimately obey the player's performative premises as they come together 
and through in action, and will vary with every delivery, for that is the nature of the performative act. The same may apply, perhaps, to the practice of criticism concerning this sonnet.

In order to set text into action, the main challenge is precisely to determine a basic action device, or frame of action, inside which to develop the overall performance. In the case of performing sonnet 129, this implies locating (or re-locating) the voice. In the present reading, it would come straight from the speaker but not necessarily from the "poet" - that is, not from lyrical inwardness but from dramatic persona: 129 has the advantage of being, like 94, most impersonally "voiced". Curiously, this makes it suitable for direct, bare-stage, delivery. Except for the "bait" simile, which nonetheless adds little by way of figure, 129 consists of instances of direct speech that make the player's body the sole site of realization of performance. Hence, a scenario for sonnet 129 would be fairly uncomplicated with regard to the performative elements to bring into play but quite demanding on the player's body, above all on his/her ability to modulate voice, gesture, and facial expression.

Sonnet 73 poses other problems.

That time of year thou mayst in me behold,

When yellow leaves, or none, or few, do hang

Upon those boughs which shake against the cold,

Bare ruined choirs, where late the sweet birds sang;

In me thou seest the twilight of such day

As after sunset fadeth in the west,

Which by and by black night doth take away,

Death's second self, that seals up all in rest;

In me thou seest the glowing of such fire

That on the ashes of his youth doth lie,

As the deathbed, whereon it must expire,

Consumed with that which it was nourished by;

This thou perceiv'st, which makes thy love more strong,

To love that well, which thou must leave ere long. 
The chief questions remain the same, of course: to locate voice and conceive of a ruling action or frame of action. At first glance this looks simple enough, and simply it has been expounded in critical tradition. According to traditional reading, there is an older speaker, an " $\mathrm{I}$ ", who addresses a younger "other", depicting in tripartite fashion what that "other" perceives of the "I" before sinthesizing such perceptions into a general conclusion where the "I" tells the "other" how ironic it is that the latter's love for him should grow stronger as his life grows shorter. Often this relationship is described as one between "the poet" and his beloved "youth", in the form of a fictional act of unilateral interlocution. This seemingly unproblematic description fails to address the central issue, though. As Vendler notes, "Three models of life are proffered by the speaker: although he displaces them into perceptions he ascribes to the addressee, ... they are really self-created perceptions" (Vendler 334).

Any dramatic event involves a complex and uneven triangular operation prior to its completion through the audience's reception and response. The playwright produces a representation of a fictive self (a part, a role, a character) alien to himself; but the part is actualized by and in the also but not equally alien body/self of an artistic agent, the player, who is at the same time an "other" to the part and to the dramatist. According to this, sonnet 73 involves an interesting case of dramatic method half-turned sonnet matter. Vendler identifies the commonest trick in the dramatist's trade: a sense of inwardness created just to be re-located as the inwardness of an "other" (a crafted part) that is "other" not only with regard to the creative "I" (the dramatist) but also regarding the "you" (the performer of the part). Interestingly, sonnet 73 freezes and exposes the process midway through.

In sonnet 73, perceptions are indeed displaced but in unfinished manner: not all the way to the "other" but only half-way to the "you" (therein "thou") - a complex disclosure of the artistic process within the artistic product not unlike the mise-en-abîme feats of a Velázquez, Rembrandt, or Vermeer. ${ }^{6}$ What we hear is the voice of the creative "I" in the act of dramaturgic transferral to a potential performer (to the "thou", a marker of an intermediate stage of dramatic writing and actualization), and 
not really to the performative "other". Thus read, 73 resembles a set of primal or projected directions ruling a potential performance of a text, and does not look like the text to be performed, although it is the text for performance. In other words, 73 sounds as if the play-master were directing one player regarding what he is to use as input in a scene involving two parts, speaker and addressee, a "voice-seer" and a "voice-seen", with the input thereupon becoming the scene.

In overt form, the question prompting a scenario for this sonnet would be "what do you see in me?"; however, in covert fact, that question implies the previous "what do I see in me?" This, the actual, prompt-question is necessarily bracketed thus: "[how do I see in me] that [which I will say] you see in me?" - bracketed, that is, by issues of method. It follows that the speaker and the addressee of sonnet 73 are originally one and the same, but are separated in two parts for artistic purposes, by an artistic device or fiction, with the early modern twist that its actualization takes place in full awareness and disclosure of artistic method through the foregrounding of the mediator's role. This likewise implies that speaker and addressee may be played by one and the same player, provided that we find the device, the appropriate site for the dissociation of "one and the same" into "two yet same but other" - provided, that is, that we recognize the origin of the sonnet in self-contemplation, in self-reflection.

Thus, the voice in sonnet 73 may be understood as proceeding from a mirror ${ }^{7}$ in symbolic fashion - i.e. not as the matter of a fiction of "actual" events but as a pure rhetorical fiction, the aforementioned "device", specifically the figure of a "speaking mirror". Thus, herein the voice in sonnet 73 is understood to fictionally proceed from the reflective object back to the actual subject, the subject that perceives himself. In this reading, there is no "other", except the "I" projected back to itself by the "thou": the "mirror" speaks as the "I" to the seer, who is the true "I" here but turned into a "thou" by the device. This entails reading "leave" in line fourteen not as it is usually glossed ("be separated from"; e.g. Duncan-Jones 256 n14), but in a simple transitive mode, implying that the "that" which will be "left" is the seer's own life, surely a loved thing. 
Sonnet 73, then, contains another instance of in-betweeness, correlative to the use of mise-en-abime in painting mentioned above and also hinted at in some shakespearean exchanges (e.g., Brutus's answer to Cassius in Julius Caesar: "...the eye[I] cannot see itself/ But by reflection...": 1.2.52-53). ${ }^{8}$ In sonnet 73 the apparent exchange between voice and 'other' is like a mask for a more private scene and experience, that of an aging man looking at himself, and looking for ways to relate to his own decay: looking to define decay at first in bearable, merely representative terms, only to realize how they inevitably lead to greater and greater anxiety as awareness of death grows upon him. The poet, thus, has projected an originally inward voice out onto the reflective surface, and then made it come back at the beholder of the reflected image (himself) in the form of three descriptions of three discrete instances of visual experience: a painterly depiction of late autumn, a somewhat distant observation and sketch of a landscape with sunset, and an urgent, close, private and very quick glance at a dying fire in a fire-place.

All three images are deceptively aimed as if to an "other", an observer who is, at once, the observed one, who in all three cases is deceptively "framed" within a "present" of visual contemplation that makes one perception collapse with the next in impossible simultaneity. As mentioned above, artists of the early modern period would do this, and they would do it with mirrors. Obviously, Velázquez, Rembrandt, and Vermeer did not originate the use of mirrors to produce paintings; yet they - and others in their era - turned such use into active input for a particularly playful and at once anxious mode of painting, especially where the painter himself was a subject - a self-acknowledged witness to self in action and/or decay. Previous painters would exclude all overt traces of the use of mirrors, or else, as Van Eyck and Metsys, for instance, would acknowledge the presence of a convex mirror, and their own presence in that mirror, with pointedly allegorical, analogical, or cryptic aims.

According to Debora Shuger, "One would be hard-pressed to find any early-modern English instance of mirroring used as a paradigm for reflexive self-consciousness. With the exception of Richard II, no one looks in the mirror to find out what he looks like, to view himself" (Shuger 31). Indeed, in Shakespeare there are enough direct depictions of mirror use that seem to 
confirm her views: not only in sonnets 3 and 24, to mention just a couple, but in Antony and Cleopatra, Julius Caesar, Troilus and Cressida, Hamlet, King Lear, and so forth, where looking glasses are shown to perform almost any function but that of "reflexive self-consciousness". Still, an exception to what Shuger sustains may be found in sonnet 62, considering that Shakespeare's "complex system of reflections in Sonnet 62 evokes a speaking self that does all sorts of things in front of the mirror. It preens, self-castigates, peeps modestly from behind self deprecating images, and even threatens to absent itself altogether" (Kelly 3). Richard II may not be alone in seeing himself in a looking glass, then

All that notwithstanding, shouldn't acknowledgement also be made of instances where the use of mirrors isn't overt but still perceptible, only implicit in the fiction, as in the present case, as the origin of the fiction, an origin reflected, so to speak, in the very fabric of the fiction? It is quite possible, for instance, to recognize the traces of a poet, or of his poetic persona or speaker, looking at himself in a mirror at the origin and core of other sonnets. Sidney's 31 from Astrophel and Stella would be an appropriate instance.

With how sad steps, O Moon, thou climb'st the skies!

How silently, and with how wan a face!

What! May it be that even in heavenly place

That busy archer his sharp arrows tries?

Sure, if that long-with-love-acquainted eyes

Can judge of love, thou feel'st a lover's case;

I read it in thy looks-thy languished grace

To me, that feel the like, thy state descries.

Then, even of fellowship, O Moon, tell me,

Is constant love deemed there but want of wit?

Are beauties there as proud as here they be?

Do they above love to be loved, and yet

Those lovers scorn whom that love doth possess?

Do they call virtue there ungratefulness?

On the surface of it, Astrophel simply addresses the moon as it "climbs the skies" "silently" with "sad steps" and "a wan face", as would a 
melancholy lover, the likeness of Astrophel himself, who considers the moon to be of his "fellowship". The sonnet is allegorical in fashion - the "thou" does become an "other" — but it clearly has its origin in selfcontemplation: Sidney's treatment of the scene as a private "conversation" between his fictive persona, Astrophel, and a silent "other" that is really meant to serve as a self-reflective device, suggests that Sidney recalled or imagined the pitiful looks of a dejected lover (Astrophel himself) in a mirror and exquisitely transfigured them to the moon. Let us remember that, at least ideologically, in early modern times the moon - understood as analogous to silver and therefore to water, possessing no light of its own but reflective of the sun's golden and fiery one - was understood, manipulated and employed artistically, allegorically, astrologically, and alchemically as a mirror.

This is also consistent with Shakespeare's sonnet 62, where the speaker begins by "thinking himself" one thing (an ideologized representation: "I all other in all worths surmount"); then quite the opposite after avowedly looking at himself in the mirror (an experiential representation: "Beated and chopped"); to conclude by condensing, however conventionally or artificially, himself with the other's self ("'Tis thee (my self) that for myself I praise"), thus making "I" and "Thou" "one and the same" and still two ("yet same but other") in order to "paint my age with beauty of thy days". In sonnet 62 , that is, the speaker re-elaborates his (unsatisfying actual) self as an artistic object by and in the "thou", towards the realization of the "other", the performed product. As artistic endeavors, the mirror-games that these sonnets play - as well as the mirror-games found in Las meninas, Vermeer's The Allegory of Painting, or the deposition scene of Richard II - playfully challenge Umberto Eco's appreciations on mirrors:

Se l'immagini dello specchio dovessero essere paragonate alle parole, esse sarebbero simili ai pronomi personali: come il pronome io che se lo pronuncio io vuole dire "me", e se lo pronuncia un altro vuole dire quell'altro. Tuttavia può accadermi di trovare un messagio in una bottiglia, con sopra scritto "io sono naufragato nell'arcipielago Juan Fernandez" e saprei pur sempre che un altro (qualcuno che non sono io) è naufragato. Ma se trovo uno specchio nella bottiglia, una volta che abbia compiuto il considerevole sforzo di tirarlo fuori, vedrò sempre me 
stesso, chiunque lo abbia inviato come messagio. Se lo specchio "nomina" (ma chiaramente si trata di una metafora) esso nomina un solo oggeto concreto, ne nomina uno per volta, e nomina sempre e solo l'oggeto che gli sta de fronte. In altre parole, qualunque cosa una immagine speculare sia, essa è determinata, nelle sue origini e nella sua sussistenza fisica, da un oggeto... (Eco 20)

Considering that Eco's assertions assume an exclusively sequential correlation of two possible participants each time, his supposedly unshakable logic must make an exception every time mirror contemplation is artistically manipulated to import the interplay of more than two instances in the exchange - as in the paintings mentioned above, in the genesis of Sidney's 31 (though maybe not in its end-result), and in Shakespeare's 73. Such exceptions are opposed to the singleness of interaction implied in Eco's example insofar as they dramatize "I" as "beholder", "beheld" and "other", at once.

One reason why Shuger considers that in the early modern period "no one looks in the mirror to find out what he looks like" resides in her well substantiated conclusion that "The majority of Renaissance mirrors - or rather, mirror metaphors - do reflect a face, but not the face of the person in front of the mirror. Typically, the person looking in the mirror sees an exemplary image, either positive or negative" (Shuger 22). Adding a key note, Philippa Kelly concurs that mirrors were "instruments of correction; platonically-angled, upward-tilted mirrors intended to reflect paradigms of virtue; remembrances of mortality; and cruel reminders that sins like that of vanity must be punished" (Kelly 4). "Rememberances of mortality" is a phrase that could well serve as a (sub)title to sonnet 73. Such reminders abounded in the period, for sure; a period when "Specular perception ... is offered as the place of mediation between the material and the spiritual, between the finite and the inifinite" (Melchior-Bonnet 119). This is consistent with the fact that Shakespeare's 73 deals with the time/space between being and not being; with the ever narrowing borders or limits between two states or realities of the self; ultimately, with what may be termed points of articulation of mirroring images: autumn becoming winter, day becoming night, fire becoming ashes, or the nearly imperceptible limit between "burning" and "burnt", the narrowest margin of all. It is also finally consistent with the sonnet's ending, the couplet, inasmuch as the 
spaces where deep irony and paradox occur are just as crepuscular, at the limits of what is and/yet is not.

In quatrains two and three this articulation is keenly identified ("twilight", "glowing ... in the ashes"); in quatrain one it must be deducted, but it is there, e.g. in the small variations of landscape ("yellow leaves, or none, or few"), and should be considered relevant to what follows herein; in the couplet, it is as plain as its ironic and paradoxical nature. The latter is in keeping with the fact that in the period, however, the "place of mediation" that Melchior-Bonnet speaks of doesn't signify the same as in medieval times, as it "no longer implies the idea of an anagogic step in a structured universe by which one could rise from an inferior sphere to a superior one" (Melchior-Bonnet 119). The image in the mirror, therefore, in the early modern period suffers a transformation, radical and decisive enough: its rhetorical range expands in many directions and dimensions. For instance, with regard to her characterization of the "speaking self" that looks in the mirror in sonnet 62 , Kelly argues that it constitutes more "a rhetorical self" than a "true" reflection of the self that stands before the glass, which thereupon begs the question, "if so, how far is [the image in the mirror] rhetorical?" (Kelly 3). In order to apply this to sonnet 73, part of the answer lies, perhaps, in also answering the question: what rhetorical vehicle does the poem resemble?

Among many topics of the middle ages, as John Manning indicates, the figure of "The Book of Nature" underwent a significant change in terms of rhetorical breadth. What could be viewed as a fairly stable "volume" of divine dictates, now was "more like a folio volume, its indices compendious and various, and its author, God, more a Baroque concettist than a simple preacher" (Manning 31) - a description that, on a human scale, applies well to the speaker in sonnet 129. Like the "Book", the mirror, as stated earlier, served purposes of mediation between paradigm and person, and its functions varied likewise. The subject in the mirror continued to see what it saw in terms of "exemplary images", "paradigms of virtue", "instruments of correction", and so on; but at the same time, since the beholder was no longer "firmly" placed within the "solid" (at least ideologically firm and solid) structure of God's impeccable and unidividuated "Book", "The feeling of selfhood that the mirror awakened was a conflictual one of modesty or shame, consciousness of the body and of one's appearance under the watchful eye of another" (Melchior-Bonnet 139-140). Interestingly, the emotions inscribed in the quatrains of sonnet 73 run 
from calm acceptance of aging in the likeness of a season of the year, a "natural" event in the "Book of God", through an emerging awareness of a disturbing truth (the approaching reality of death), to a full manifestation of the anxiety that such a truth imports - and all three, indeed, "under the watchful eye of another". Mirrors did register this undeniably subjective self-evaluation from self-contemplation, even when their function still remained fairly allegorical:

In entwining the physical with the emblematic, the mirror rooted the seeing self in the realm of pre-modern nonreflexivity while gesturing toward those spaces and hidden depths within the self for which there was as yet no vocabulary. Real as well as figurative, the mirror's physical reflected image spun the act of reflection into a series of often unstable epistemological uncertainties and anxieties. As an artistic function, the mirror commonly offered not a flat, stable reflection of, for instance, mortality, or vanitas, but something else: in a conflation of refracted images, it was marked by transition, moving from a physical function to a variety of often contradictory speculations. It is for this reason that so many of the mirrors represented visually and verbally are convex; representing more than one individuated image, they reflect an unstable range of speculations about the place of the " $\mathrm{I}$ " in a world marked by enormous changes (Kelly 6-7).

What sonnet 73 delivers is a visual progression that practically matches Kelly's description: from an "act of reflection" it constructs aging as a "stable reflection", a comforting allegory (autumn), then as a well-known, but darker, emblematic "reminder of mortality" (twilight), and then a metaphor of the anxiety, a "contradictory speculation", of the very experience of growing old and approaching the end (the dying fire). Very importantly, unlike the other two quatrains, this end isn't confined to or regulated by any particular time scheme or frame, but can take place any moment, anywhere, anyhow, and is thus closer to the complexity of the "epistemological uncertainties" often found in Shakespeare's dramatic work.

Summing up, the speaker in sonnet 73, the voice, shows an "other" what is perceptible in himself through three separate, and more importantly, artistically differentiated depictions or "speaking pictures" of his appearence in ways purporting to be "meaningful", maybe "exemplary" ("this makes 
thy love more strong"). All three rhetorical figures look back to one source, really: the signs of aging in the speaker. Even though these signs of aging suggest three different qualities of perception - one in each quatrain - the subject cannot place those instances of perception in the "[I]eye[thou]" of his speaker-mirror without having seen the signs before in himself, necessarily through that looking glass, before translating them into the rhetorical vehicles that each quatrain develops.

More importantly, however, "the glass" is assimilated in the fiction that it promotes and becomes totally concealed, and this fiction, this rhetorical vehicle for the self-perception enabled by the mirror, is necessarily very elaborate, for it must comply with the elaborate nature of the rhetoric that up to that point in history used to overdetermine the presence of mirrors in art. To a great extent, the rhetoric involved in mirror images remains one of "example" and "paradigm", since the early modern subject "is not uninterested in the relation of the reflected self to the cosmos"; but the relation has grown very complex, so much, that this subject "uses the mirror as a highly emblematic means of exploring the boundaries and the complexities of this relation" (Kelly 6). Consequently, the reflective surface where the subject perceives and negotiates such complexities can hardly be thought of as "a polished mirror, which reflected exclusively Christian, spiritual truths" but rather as "a dark glass, a cipher, a labyrinth of significance" (Manning 31). The mirror now "imposes distance and separation within a formerly closed system" (Melchior-Bonnet 131).

For Shuger, in the earlier stages of the early modern period "one encounters one's own likeness only in the mirror of the other. Renaissance texts and emblems consistently describe mirroring in these terms, which suggests that early modern selfhood was not experienced reflexively but, as it were, relationally" (Shuger 37). This affirmation applies very well to the cases she explores, where mirrors are expressly there, and to a point also to sonnet 73 . But literally in the end, sonnet 73 operates conversely, as its third quatrain counterpoints the previous two with notes of subjective anxiety, and its couplet grows correspondingly ironic and paradoxical - even cryptic. For, what does "this" refer to in the last lines of sonnet 73? It is very hard to establish with any precision beyond that "this" is aging, for in spite 
of also pointing to their common subject, the first two ways to approach it are so different from the third that "this" acquires multiple meanings, and thus moves away from the basic allegorical function originally characterizing the merely "relational" quality of the image. My speculation is that 73 constitutes an exception to the exclusively relational, non-reflexive, experiences of selfhood that Shuger describes, insofar as it conveys selfawareness originating in self-contemplation; and yet, it does so in keeeping with the requirements of a certain rhetoric that dictates the full dismissal of the actual mirror from the poem - even though its initial presence cannot be denied - while the truly important matters that it has revealed to the "observer" prior to writing are highly elaborated in writing as being those of the "other".

Sonnet 73 , then, can be approached not only as a poem wherein voice stems from a mirror, or is fictionally and symbolically located in a "speaking" mirror, but as it derives from the image of someone who has looked at himself in one, and as that image "says" things to him that are presented as "dear" to an-other, then, by extension, 73 is also a poem that provides an "example", or better yet,"examples", to any other. Drawing on the "emblematic means" that Kelly talks about, the inclusion of "emblems" in Shuger's statement, and the fact that emblems "were 'invented' in the sense that contemporary rhetoricians used the term" (Manning 48), sonnet 73 can be compared to the brief accompanying text, the explanatory text, of an emblem; in this case, specifically the pictorial emblem of a mirror speaking thus: "In me thou seest...", i.e. the emblematic picture of a looking glass purporting to "show" three different ways of understanding the nature and process of aging and its necessary end. Sonnet 73 may even be said to contain a sort of motto, the defining verbal imprint of the picture intended to remain in memory: "This makes thy love more strong". "One cannot understate the variety as well as the pervasiveness of emblematic modes of thought and expression during this period" (Manning 16). A picture of this sort would make a very proper emblematic representation, for it woud fit right in the set of numerous emblems depicting "positive" and "negative" forms of perceiving and embracing (or not) God's gift of life, as well as His 
unquestionable, and approaching, final sentence: a "Memento mori" implying images of "Ars vivendi" and of "Ars moriendi".

The epigram or explanation in an emblem "would be occupied in setting out and explicating the meaning of ... recondite facts and problems not so much because they were difficult and strange and required explanation but because they implied some useful advice that might be applicable to one's everyday life" (Manning 48). In this regard, it may be further suggested that each of the quatrains operates independently from the others also as if each were an emblem in its own right: all three are images that may easily be kept in the "vaults" of a mnemonic system resembling, for instance, a building or a house (a "device" of memory cherished in early modern times), to be recalled precisely as a "speaking picture" when necessary; also, all three are described in ways that make them easy to visualize as well as immediately eloquent. Moreover, since the "pictures" are contained in the poem, the quatrains could be described as specially interesting "naked" emblems - i.e. emblems without an actual picture to go with them. After all, the very originator of this tradition, Alciato, considered himself a poet rather than a visual artist, and "was more interested in the fact that images could acquire or be endowed with meaning, could be used to communicate ideas" than in producing material images, for ultimately "the nub of the emblem ... lay in its gnomic allegory - not so much its image, but the compressed verbal utterance" (Manning 48).

This is not to suggest that the sonnet was actually intended as a motto and explanatory text to an emblem - or a related series of three emblems - nor that it should be read as such, but rather that, given its origin in self-contemplation and its highly organized rhetoric, it can profitably be thus "figured forth" (to quote Sidney). The fact that it is (just coincidentally?) structured in three parts - a very frequent feature of emblems - has much less to do with this proposition than that it presents three items that are definitely pictorial as vehicles for its argument, and "speaks" in ways that strongly resemble what an emblem, in this case, of a mirror, would "say" to make "example" of these things. Rather, the profit in this speculative operation would be precisely in the exception, not in the 
rule. And the exception, of course, consists in the fact that this is Shakespeare, and thus in no way can we stay at ease simply with the idea that what is written in sonnet 73 is intended to be solely "exemplary". Rather, the mirror in which his speaker looked at himself, prior to transforming his self-perception into the "other"'s perception of himself as if to deliver the type of "mirror of virtues" that emblems of medieval and early modern times would usually provide - is a mirror that "hardly reveals any kind of iconic reality, distorting the 'real' with which it identifies itself. It no longer hides a secret - the secret is henceforth in the mind that perceives and recognizes the resemblance" (Melchior-Bonnet 131).

That is, the voice in sonnet 73 that is placed in the "other", who is shown to see the "one" as example, as a "speaking picture" of what living finally entails, not only speaks of aging as a "natural" and inevitable, and ultimately acceptable, state: not only provides the pictures of aging, as it were, "for better" (quatrains one and two), but it also speaks of its "for worse" (quatrain three). Quatrain three presents the picture of a constant process of consumption involving a past that, if gone, is still eloquent in the testimony of its consequences ("the ashes of ... youth") and capable of prompting ironies and paradoxes ("consummed with that which it was nourished by"). It presents a process that knows no rules of time and place and, unlike the cyclic images of a season or a day, leads to an end from which there is no return. More importantly, it creates an atmosphere of subjective perception of decay that is in deep contrast with the objective pictures of autumn and twilight: not a picture of "moving on" but of "being and at once ceasing to be here and now" that undermines the sobering effects of its predecessors. What this imports is a radical difference in aesthetic orientation, characteristic of Shakespeare: a move away from traditional purposes and means, ideas and perceptions, in art-making, towards more powerful, complex, products of critical and provocative art, much like what he did with he entirety of his sonnet collection: write against the grain of a tradition that had very much ran its course and had thus become stale. Sonnet 73 , as if it were a miniature ars poetica, demonstrates the differencs in quality and depth between prior and new modes of 
"seeing" subjects and prior and new treatments of them in poetry.

Can a performative scenario derive from this complex source, theme, situation, and voice: the motto and text to an emblem of a "speaking mirror" intended to "show" differing visions of aging, not so much in prescriptive as in highly subjective manner? To perform sonnet 73, the evident (not the best) point to start from, though not necessarily to pursue in lineraly fashion, would be the sight of an aging man looking at himself in a mirror, from which the sonnet's text would proceed, albeit not actually but implicitly, and surely ambiguously. Perhaps a better correlative to this obvious premise could, instead, be the image of a painter pondering the framing, angle, lighting, distance, proportion, perspective, depth of field, chromatic range, axis, and whatever else applies, to the production of a painting - specifically a (self)portrait - with the aim of making the considerations in the sonnet play active parts in the artistic product, thereby problematizing whatever assumption may be made of conventional visualization as testimony of experience - for Shakespeare's 73 stands close to the art of coetaneous painters whose achievements coincided strongly with the development of flat mirrors and their complex deployment for characteristically early modern modes of pictorial representation:

The convex mirror [like the one in Van Eyck's Arnolfini Portrait] concentrated space and offered a global and spherical view of the world, embracing many perspectives, but its roundness distorted the image. The plane mirror, on the other hand, offered an exact but only partial image, a framed vision from a single point of view that controls what is seen like a stage director. A model of knowledge that is no longer symbolic and analogical but rather critical and discursive, the mirror finds its place in a new philosophy of representation, responding to its own rules, and in addition to its role in organizing space, it revels in the pleasure of the spectacle (Melchior-Bonnet 128).

Such modes of pictorial representation enable the presence of irony, sense of humor, and drama in the particular work of art, through individuated, standards.

The expressly literary features of sonnet 73 reflect the aesthetic transition mentioned above: the differences between the exquisite art of ideologized allegory and one of rougher, sharper and darker hues, more 
appealing to the modern eye[I], more frequent with Shakespeare. Each quatrain in sonnet 73 discretely conveys a self-contained perception of the decaying self, increasingly closer to dying, in the form of a "picture", a term dear to Sidney throughout his Apology. Shakespeare may be imagined as having drawn on his knowledge of Sidney's sonnets for a "figuring forth" of self-in-the-mirror as a portrait of ambiguous despair. Just as well, however, we may also imagine Shakespeare as drawing against Sidney. The artistic method of 73 ultimately differs as radically from Sidney's 31 as 129 disavows the conventional views on sex that it draws upon. If Romeo and Juliet demonstrably rests on Sidney's art of the sonnet, it just as strongly contests it. Likewise, where in Sidney's 1 we surely find a miniature ars poetica, in Shakespeare's 73 we may find its opposite - not the contrary of an ars poetica but a contrary one: one that rejects the beautiful but simple and outdated allegorizaton of aging through the placid and comfortable image of autumn turning into winter in painful favor of the sharper, pressing and real image of a flame dying out - one well in keeping with the anxieties of an emerging selfhood. Between them is a bridging look at another common representation of decay that, unlike the first, does implicate death, the ovelooked term in the easeful allegory of aging as a season of calm. Sonnet 73, then, may be read as a poem that syhthesizes some of Shakespeare's views on what constitutes an intellectually and aesthetically rewarding representation, herein of growing old, by providing three examples of it, where the third is, for all its faults in the eyes of the previous tradition if compared with the opening one, the only choice to apply in times such as the emergent self had, and continues, to confront.

As mentioned above, all three quatrains of 73 are "framed" as a picture would be - as framed as their source is, the mirror - and all aim at "figuring forth" a "likeness of death". Still, each employs a discrete and contrasting poetic approach. Although such methods may be well characterized in comparison with painting, it must be noted - as Joseph Pequigney does (Pequigney 292) - that the "pictures" (Sidney's "speaking pictures") inscribed in sonnet 73 are remarkable not so much for their inherent pictorial or visual qualities but because of the highly effective ways 
in which they are written. Deliberately or not, sonnet 73 effects a quick revision of former, prescriptive, allegorical, and vertically sanctioned modes of literary representation (quatrains one and two), leading to a practical commitment to an equally common figure, that of the dying fire, but now depicted by means of more individuated, critical, and freely fluctuating writing procedures rooted in complex experience and contingency (quatrain three), before concluding in a proposition of paradoxical ambiguity (couplet). To translate this into performance, we have to consider how Shakespeare seems to have applied principles of composition proceeding from static to dynamic, from general to particular, from received to personal, from transparent and highly organized to obscure and highly selfcontradictory, and from conventional to ironic. The result is a triptych-like poem practically disavowing forms of poetry that may be called ideal / authorized in favor of other, that may be termed experiential/critical; 73 is indeed a miniature ars poetica problematizing the very notion it embodies.

Quatrain one offers a likeness of aging and decay that is basically unproblematic, comforting with regard to the theme it addresses, not least because it strongly foregrounds the "cyclicity" that Vendler speaks of (Vendler 334). Its depiction of middle-to-old-age in the guise of late autumn - in keeping with the conventional "ages of man" figure - resembles a painting made in the form advocated by Alberti and realized in, say, Il Perugino's Handing of the Keys in the Sistine Chapel: static, all-encompassing, calmly celebrating the ideological principles of Christian life, not its particular contingencies. It is as if upon seeing the image in the mirror the speaker had automatically resorted to a set, highly organized, mode of representation of the self therein reflected to transform shock into an inherited comforting conviction, shunning present despair. Moreover, in its initial evocation of "ruins" (despite its being made with respect to recent ones) this quatrain is consistent with the usual and necessary inscription of pictorial representations of this kind within the larger frame of humanist tradition by means of objectively acknowledging indices of artistic and ideological continuity in the body of the work. 
This luminous and calm landscape, then, is such $a b$ ovo: a received idea of what aging, the object of representation, must be like in order to find an appropriate place in the larger picture, the ideological construct of living well and dying well - Ars vivendi and Ars moriendi. As such, it could hang on a wall as a reminder of what aging must look like: it isn't, to paraphrase Sidney, "brazen nature" but "excellent Idea". The quatrain, verbal art, makes verbal what in pictorial representation is visual. But this happens in each quatrain with increasing differences; in fact, it constitutes the ultimate mark of the sonnet's practical challenge of convention. In quatrain one, the elegantly paced rhythm, pristine rhyme, fluid enjambment, make an exquisite acoustic fabric featuring a predominance of soft consonants and open vowels. This reaches its peak with the diphthongal feat of "bare ruined choirs..." that silences the isolated "shake" - the only, very minor, intruder in this picture of serenity. All these phonic ingredients are strictly controlled for pleasant and sobering effect. Death, the ugly contingency underlying all this, is not even mentioned; in fact, it need not be, for it has been properly assimilated and allegorized into a timeless image of what must be acknowledged and accepted as "natural" - ironically, the passing of time.

Quatrain two, on the other hand, though equally framed as a conventional allegory of decay in the form of "black night", makes death half-explicit as a member of a conventional figure of speech ("Death's second self"), thus establishing a conspicuous link with the "deathbed" of quatrain three, where the dreaded actual subject of the poem becomes a solid, objective item, despite also being a member in a figure. In this sequence of ideological concealment, comforting half-disclosure, and fully conflicting acknowledgement of the anxiety of growing old and hence approaching death, quatrain two serves as a bridge between the "timeless" and conventionally beautiful (though exquisite) quatrain one, and the fully "dramatic" and nearly ugly quatrain three. Quatrain two is slightly but decidely more dynamic than quatrain one. In pictorial terms, it would belong somewhere between the still luminous but surprisingly, though almost imperceptibly, dramatic late Perugino who painted the hands of the Virgin in the central panel of the Galitzin Triptych, and the still tentative but 
already effectist young Veronese of the Crucifixion at the Church of Saint Sebastian in Venice.

Quatrain two inscribes the passing of time in simple, almost matter-offact, fashion with the support of an isolated instance of soft alliteration, "by and by black night...", that becomes dramatically conspicuous by emerging within a phonic layout of a very different kind. For the acoustic fabric of this quatrain consists of a pervasive combination of $/ \mathrm{s} /, / \mathrm{t} /$ and $/ \mathrm{th} / \mathrm{sounds}$ : "THou SeeST THe TwilighT of Such... afTer SunSeT fadeTH in THe weST... nighT doTH Take..." that brings the voice down to murmur-like, if slightly harsh, level, prologuing a turn to introspective darkness in quatrain three. A sensation that the restful autumn picture that preceded this was but a "colorful deceit" increases as this phonic layout reaches a point of saturation: "deaTH'S Second Self THaT SealS up all in reST". The rhymes of lines six and eight, ending ST, become hardly distinguishable from the rest of the acoustic fabric. Although quatrain two may be said to still offer ideological shelter from despair (cyclical rest towards a "new day"), it clearly begins to erase the apparently solid line of defense dividing "dying well" from just dying.

With quatrain three we reach the collapse of neatly organized representation: the prescribed beauty of "seeing" and thereby accepting a comfortable representation of aging and approaching death is fully replaced by a present, urgent image of consumption lacking the beauty and the relief that the image of autumn was intended to conventionally provide in earlier times. Quatrian three skews stable, fixed, received, and comforting ideas and favors the chiaroscuro of anxious experience and ambiguous response, what may be thought of as the actual perception of the actual image in the mirror, perhaps somewhere between dramatic Reni, sarcastic Veronese, and violent Caravaggio. Vendler's characterization of a decisive difference between the quatrains suggests the hardness of this free-fall: "the third quatrain ... abandons the linearity - early to late - of its predecessors in favor of a stratified verticality" (Vendler 335). Moreover, and only too evidently but still important to reiterate, quatrains one and two liken aging to cyclic processes - or in the former, perhaps even a specific, fully pictorial allegory of age, not of aging - while number three compares it to late stages of a 
process that closes on death, one that bespeaks finality without return, somewhat closer to the true contents of human truths.

Once again, the acoustic fabric is key. The previous saturation of $/ \mathrm{s} /$, $/ t /$, and / th/ sounds in line eight, and the lack of clear distinction between the even rhymes and the general sounds in quatrain two are nothing compared to the frictions, fractures, and failures inscribed in quatrain three. Not music but organic noise informs the aural backdrop of it. Its rhymes are unpleasant and almost totally indifferent: "fire", "lie", "expire", and the clumsy "by" convey extreme and exhausted physical strain and awkwardly exhaling open-mouthedness in sharp contrast/complicity with the persistent and increased murmur-like effect of the $/ \mathrm{s} /, / \mathrm{t} /$, and $/ \mathrm{th} /$ sounds that carry from quatrain two and now give way - just as the exquisite vowels, harmonious consonants, delicately proportioned rhythms, carefully chosen rhymes of quatrain one had previously given way to them - to a fast selfcollapsing disarray of even harsher combinations of $/ \mathrm{h} /, / \mathrm{sh} /, /$ ts $/$ and /cs/ sounds on top:

in me THou SeeST the glowing of SuCH fi [ah] re THaT on THe aSHes of HiS youTH doTH li [ah] e aS THe deaTH bed whereon iT muST eXpi [ah] re conSUMMeD wiTH THaT WHiCH iT was nouriSHed[T] by [ah]

As each quatrain mirrors the "you" that each is to the "other" at everaccelerating pace, the foundation of the sonnet slides down the mirror, now a conic one, towards its imperceptible vortex with greater speed at every word. In the end, the voice that "speaks" from the mirror does so not so much to provide "examples" of how to construct decay and death in "good" fashion, but rather to dismiss such constructions in full view of more obscure, and more compelling, reflections on such subjects. Aging, after all, is as private and particular as it is pressing and leads to the ironically permanent state of ceasing to be.

Specifically performative qualities of sonnet 73 are well mirrored in this: as each quatrain develops, we not only move from long through short to immesurable shorter time (as has often been pointed out) but likewise from quiet splendor through growing shadows to darkness dimly lit by 
dying fire; from open through narrow to infinitely small distance in time between the beginning and end of a process (a season, a day, the instant from burning to burned) and the infinitely small space suited to that time; also from widest through medium to impossible angle; and ultimately from absence of anxiety, through hinted concern, to always being aware and living and dying one's own death at once. In this miniature, self-conflicting, ars poetica, we reach the point where ugly amounts to beauty in a final, dramatic, counter-figuration of timelessness (static autumn), through noticeable time (twilight), to ungraspable instant (dying fire). A performance of 73 would demand an equally complex scenario aiming at an overall "spiral-conic" effect by starting, in concealed fashion, at a vortex with two self-images, those of the speaker and of the mirrored self, which may be newly reflected in the mirror, sending the self-in-the-mirror back to the vortex where time, space, self, and self-image collapse in reflection as the light fades out because the fire dies out as it lives on and hopes to remain. It may be worth a try.

Among the many fears that a mirror induces, a common yet most disquieting is that of being sucked into one - not so much because one might disappear from the world, but because one would disappear into one's converse self, into the vortex of one's own, (un)desired but (in)dispensable, "picture", "you", or "other". Sonnet 73 seems to achieve the maximum disquieting effect in the deceptively simple way it inscribes the collapse of overdetermined representation - the collapse of what, if mirrors did not exist, would stand unquestioned as the sole common denominator of selfhood, a shadow necessarily alien to selfhood - into an endlessly selfconstructive/ self-destructive act of language: irony.

At starting the act of language was 'what do you see in me?' meaning 'what do I see in me?' bracketed by 'how can I see in me that I will say you see in me?' The couplet in the mirror answers all with the greatest (im)precision: "you see this that makes [thee] love that..." The prompting question of the poem, and of its potential performative scenario, is kept as valid as unanswered. The couplet of sonnet 73 writes and performs at once one of the many versions of the simplest and best Shakespeare play there is: The play of 'this and that' or What Shakespeare Will. In one of its visible versions 
Michael R.G. Spiller and Joseph Pequigney share the same basic scenario, with Shakespeare playing the same part: that of the early modern poet exercising his deceptive art to achieve the immortality of poetic recognition. Spiller epitomizes it by means of Horace's "Non omnis moriar, multaque pars mei / Vitabit Libitinam...". I'm afraid that I cannot really hear much with my eye beyond the fictional title of that fiction of a real play with a fake title I played with above. Hence, I can only say that, hopelessly, sonnet 73 whispers "Libera me Domine de morte aeterna".

\section{NOTES}

1. A phrase unsurprisingly close to Shakespeare's sonnet 23.13: “To hear with eyes...".

2. All quotations from Shakespeare's sonnets follow Duncan-Jones edition.

3. For instance, see Petrarca's In vita 132: "S'amor non è, che dunque è quel ch'io sento?", or a variation, say 145: "Pommi ove 'l sole occide i fiori e l'erba" (Surrey's "Set me whereas the sun doth parch the green"); or Lope de Vega's famous 'Defintion of love': "Desmayarse, atreverse, estar furioso,/ áspero, tierno, liberal, esquivo,/ alentado, mortal, difunto, vivo,/ leal, traidor, cobarde y animoso...", and so on.

4. I do not seek to contest Vendler's far superior reading. Her interpretation of 129 as creating a tension between received notions and experience of lust is remarkably persuasive and pleasurable, not least because it foregrounds the sharp sense of dramatic irony and paradox found in the sonnet. My goal is to substantiate a reading necessitating quatrain three to remain more impersonal than she sees it. There is, then, another option. Our speaker might deliver quatrain three as if inspired by his own reading of conflicting views on lust, views of a more "literary" sort, perhaps even some of his own earlier attempts at dealing with this "heaven/hell" (not sex, but his present situation in connection to sex), now perceived as either inadequate or irrelevant.

5. I would not consider similar passages in the plays to serve the purpose.

6. The closest parallel in a play that I can think of is Lady Macbeth's speech at the beginning of 1.5. As she addresses (absent) Macbeth's 'thou', she performs a dramaturgical input to his part: "Thou wouldst be great, art not without ambition...". 
7. This (re)location of voice in the mirror is in agreement with Vendler's perception that the speaker "has ascribed these readings to the beloved to represent the beloved as a mirror perfectly reflecting the speaker's own self-image" (Vendler 336), save that with her "mirror" is more a figure of speech than the suggestion that it constitutes an actual instance in the artistic process of the fiction informing the sonnet (as is the case with Pequigney, 291).

8. The letter Lady Macbeth reads before her speech in 1.5 serves the symbolic function of a mirror - as does the one that Brutus reads in 2.1, Malvolio in 2.5, and so on. Lady Macbeth sees herself in the dramaturgical input Macbeth's letter provides ("This have I thought good to deliver thee, my dearest partner of greatness..."), thereby starting the mirror-game that her ensuing speech will complete as suggested above.

\section{References}

DunCAN-JONES, Katherine (ed.), Shakespeare's Sonnets(1997). The Arden Shakespeare ( $3^{\text {rd }}$. series), London: Thomson Learning.

ECO, Umberto, Sugli specchi e altri saggi(1985) Milan: Bompiani.

KelLy, Philippa. "Surpassing Glass: Shakespeare's Mirrors." Early Modern Literary Studies 8.1 (May, 2002): 2.1-32, disponible en $<$ http:/ / purl.oclc.org/emls/08-2/kellglas.htm >.

MANNING, John, The Emblem(2002) London: Reaktion Books.

MELCHIOR-BONNET, Sabine, The Mirror: A History(2002). New York and London: Routledge.

PeQuigney, Joseph, "Sonnets 71-74: Texts and Contexts", in Shakespeare's Sonnets: Critical Essays(1999),James Schiffer(ed.) New York and London: Garland Publishing.

SCHOENFELDT, Michael C., Bodies and Selves in Early Modern England: Physiology and Inwardness in Spenser, Shakespeare, Herbert, and 
Milton(1999). Cambridge: Cambridge University Press (Cambridge Studies in Renaissance Literature and Culture 34).

SHUGER, Debora, "The 'I' of the Beholder: Renaissance Mirrors and the Reflexive Mind", in Renaissance Culture and the Everyday(1999), Patricia Fumerton and Simon Hunt (eds.). Philadelphia: University of Pennsylvania Press.

SPILLER, Michael R.G., The Development of the Sonnet: An Introduction (1992). London and New York: Routledge,.

VENDLER, Helen, The Art of Shakespeare's Sonnets (1997). Cambridge and London: Harvard University Press. 